\title{
Neurorehabilitation in Persons with Multiple Sclerosis: Scientific Basis and Options of Treatment
}

Angelo Pappalardo ${ }^{1,2 *}$, Emanuele D’Amico ${ }^{1}$, Clara Chisari ${ }^{1}$ and Francesco Patti ${ }^{1}$

${ }^{1}$ Department of Rehabilitation, Azienda Sanitaria Provinciale di Catania, Catania, Italy

${ }^{2}$ Multiple Sclerosis Center, University of Catania, Italy

\begin{abstract}
Introduction: Multiple Sclerosis is the leading cause of no traumatic disability in young people. Nowadays, neurorehabilitation is commonly prescribed in patients with MS, but there are still some issues to be explored further. In this review, we discuss the following topics: 1 ) the neuroscientific basis of neurorehabilitation in multiple sclerosis; 2 ) what would be the ideal set of rehabilitative treatment: inpatients, outpatient or home-based therapy?
\end{abstract}

Methods: A systematic search was made, using combination of the following terms: rehabilitation, multiple sclerosis, disability, plasticity, motor learning, cognitive rehabilitation, quality of life.

Results: A growing amount of evidence suggest that motor and cognitive rehabilitation may enhance functional and structural brain plasticity in patients with multiple sclerosis. Improvement of function seems to be correlated with functional Magnetic Resonance Imaging changes in brain. Moreover, several studies show the effectiveness of cognitive rehabilitation to improve some domains of neuropsychological functions, such as attention, information processing and executive functions.

Regarding the rehabilitative setting, it should be chosen taking into account the personal needs of each patient. All the studies, performed in different setting, demonstrated the effectiveness of rehabilitation in Persons affected by multiple sclerosis.

Conclusion: Rehabilitation is effective in mitigating disability and improving QoL in persons with MS. Setting for rehabilitation treatment should be chosen taking into account many personal needs and desires of each patient.

Keywords: Multiple sclerosis; Rehabilitation; Disability; Quality of life; Brain plasticity

\section{Introduction}

Multiple sclerosis (MS) is an inflammatory and neurodegenerative disease of the central nervous system. Approximately 2.5 million persons are affected worldwide [1]. In young adults, MS is the leading cause of non traumatic disability. The impact on the Health Related Quality of Life (HRQoL) can be very heavy and dramatic [2-6].

MS is a disease with a remarkable heterogeneity in clinical course, neuroradiological features and involvement of susceptibility gene loci. MS phenotypes can be categorized as relapsing or progressive in the context of current medical status and history [7].

The pathological processes involve several functional systems and consequently, the disability is a variegated world, in which the patient builds up a multiplicity of neurological deficits. In addition, the disease has an unpredictable and progressive course, which aggravates the disability over the time [8]. The variety of MS impairments and the relative disabilities determine a comprehensive medical intervention, which could be only provided by multidisciplinary programmes [9]. Within these programmes, rehabilitation can be highly useful in person with MS (PwMS). While immunomodulating drugs aim to decrease exacerbations and slow down disease progression, rehabilitative intervention has mainly different goals, which can be shortly summarised: a) improving or maintaining general health; b) mitigating impairment of function such as loss of strength; c) minimising the effects of impairment such as spasticity; d) providing adaptive strategies to minimise disability; e) providing adaptive equipment and devices, such as orthoses, canes and wheelchairs, in order to reduce functional dependence; f) training skills to improve vocational capabilities; g) giving counselling to enhance strategies of coping with the changes brought on by the disease; $h$ ) providing symptomatic management [10-12]. All these aims should be included within a multidisciplinary rehabilitation project. Lastly but not least, rehabilitation has to determine a positive impact on either mental or physical components of HRQoL [13].

For many physicians, neurorehabilitation is a difficult and fascinating challenge which, at first glance, may seem rather arduous and invincible. The first obstacle facing MS rehabilitation consists of the lingering scepticism of some neurologists, who are convinced of its relative ineffectiveness. Execution of clinical trials focused on the rehabilitation is difficult, because of the contrast between the habitually empirical philosophies of rehabilitation and the rules of evidencebased medicine. These difficulties are due to several factors, such as heterogeneity of MS patients, lack of control group, quantitative and qualitative disparity of rehabilitative intervention, concomitant treatment with either disease modifying or symptomatic medications, lack of appropriate and sensitive outcome instruments.

The effects of rehabilitation on patients with MS were studied as early as the 50s [14-20]. However, the neuroscientific basis of neurorehabilitation are not completely established. Besides, the neural substrates underlying the recovery and the functional compensation are incompletely understood in MS.

This review will address the following questions:

*Corresponding author: Pappalardo A, Department of Rehabilitation, Azienda Sanitaria Provinciale di Catania, Catania, Italy. Tel: +39-3497542419; E-mail: pange.bel@virgilio.it

Received September 05, 2016; Accepted October 22, 2016; Published October 29, 2016

Citation: Pappalardo A, D'Amico E, Chisari C, Patti F (2016) Neurorehabilitation in Persons with Multiple Sclerosis: Scientific Basis and Options of Treatment. J Mult Scler (Foster City) 3:186. doi:10.4172/2376-0389.1000186

Copyright: (๑ 2016 Pappalardo A, et al. This is an open-access article distributed under the terms of the Creative Commons Attribution License, which permits unrestricted use, distribution, and reproduction in any medium, provided the original author and source are credited. 
Citation: Pappalardo A, D’Amico E, Chisari C, Patti F (2016) Neurorehabilitation in Persons with Multiple Sclerosis: Scientific Basis and Options of Treatment. J Mult Scler (Foster City) 3:186. doi:10.4172/2376-0389.1000186

Page 2 of 8

a) May motor and cognitive rehabilitation induce functional and structural plasticity into the brain of people with MS?

b) What would be the most appropriate and effective set of rehabilitation to minimize impairment, reduce disability or improve HRQoL?

\section{Methods}

A search was carried out, using combination of the following terms: rehabilitation, multiple sclerosis, disability, plasticity, motor learning, quality of life .

The following databases were systematically searched: EMBASE
(1974 to 2015), Medline (1950 to 2016) and PubMed (1950 to 2016). The number of studies was reduced removing those not primarily about MS and the duplicates.

\section{Results}

Since the 80 s, many randomised controlled trials for rehabilitation in MS have been carried out and are summarised in Table 1 [12,21-38].

Several studies analysed the effects of the exercise training on impairment, disability and HRQoL of MS patients. Petajan et al reported that ambulatory MS patients benefited from aerobic training in terms of fitness, reduced fatigability, improved QoL perception

\begin{tabular}{|c|c|c|}
\hline $\begin{array}{l}\text { Main author } \\
\text { Journal }\end{array}$ & Subjects & Conclusion \\
\hline $\begin{array}{l}\text { Fracabandera et al. } \\
\text { Rehabil Nurs [21] }\end{array}$ & 67 patients with chronic progressive disease followed over 3 weeks & $\begin{array}{l}\text { Inpatient rehabilitation led to a } \\
\text { significant reduction of disability as compared to } \\
\text { outpatient treatment }\end{array}$ \\
\hline $\begin{array}{l}\text { Petajan et al. } \\
\text { Ann Neurol [22] }\end{array}$ & Fifty-four patients assigned to treatment or no treatment groups & $\begin{array}{l}\text { Treated group improved in } \\
\text { maximal aerobic capacity, upper and lower extremity } \\
\text { strength, all component of the physical dimension of } \\
\text { The Sickness Impact Profile. }\end{array}$ \\
\hline $\begin{array}{l}\text { Freeman et al. } \\
\text { Ann Neurol [23] }\end{array}$ & 50 inpatients with progressive MS followed for 12 months after discharge & $\begin{array}{l}\text { Improvement in disability, } \\
\text { emotional well-being and physical component of QoL } \\
\text { were maintained for a period from } 6 \text { to } 10 \text { months after } \\
\text { discharge }\end{array}$ \\
\hline $\begin{array}{l}\text { Di Fabio et al. } \\
\text { Phys Ther [24] }\end{array}$ & $\begin{array}{l}12 \text { outpatients with chronic progressive were compared with } 19 \text { similar on } \\
\text { a waiting list }\end{array}$ & $\begin{array}{l}\text { Improvements in six health status measures on the } \\
\text { Rand } 36 \text {-Item Health Survey } 1.0 \text { (SF-36) in treated } \\
\text { group. No improvement in the wait-listed group }\end{array}$ \\
\hline $\begin{array}{l}\text { Solari et al. } \\
\text { Neurology [25] }\end{array}$ & $\begin{array}{c}27 \text { ambulatory MS inpatients treated for } 3 \text { weeks versus } 23 \text { control MS } \\
\text { patients }\end{array}$ & $\begin{array}{l}\text { Treated patients improved in FIM motor domain and in } \\
\text { overall HRQoL profile }\end{array}$ \\
\hline $\begin{array}{l}\text { Patti et al. } \\
\text { J Neurol [26] }\end{array}$ & $\begin{array}{c}58 \text { outpatients assigned to the study treatment for } 6 \text { weeks and } 53 \text { to a } \\
\text { waiting list }\end{array}$ & $\begin{array}{l}\text { All SF-36 domains improved in } \\
\text { treated group }\end{array}$ \\
\hline $\begin{array}{l}\text { Patti et al. } \\
\text { J Neurol [27] }\end{array}$ & $\begin{array}{c}58 \text { progressive outpatients treated for } 6 \text { weeks, in comparison with } 53 \\
\text { progressive patients in control group. }\end{array}$ & $\begin{array}{l}\text { Improvement in disability (FIM) in treated group. No } \\
\text { changes in control group. Benefits maintained for a } \\
\text { further six weeks }\end{array}$ \\
\hline $\begin{array}{c}\text { Craig et al. } \\
\text { J Neurol Neurosurg Psychiatry [28] }\end{array}$ & $\begin{array}{c}20 \text { patients with MS relapse were treated with both intravenous } \\
\text { methylprednisolone and rehabilitation. They were compared with } 21 \\
\text { patients with MS relapse, treated only with intravenous methylprednisolone }\end{array}$ & $\begin{array}{l}\text { Patients treated with both steroids and rehabilitation } \\
\text { showed significant differences in the Guy Neurologic } \\
\text { Disability Scale, Amended Motor Club Assessment, } \\
\text { Barthel Index, Human Activity Profile and SF-36 }\end{array}$ \\
\hline $\begin{array}{l}\text { White et al. } \\
\text { Mult Scler [29] }\end{array}$ & Eight MS subjects volunteered for twice weekly training sessions & $\begin{array}{l}\text { Knee extension }(7.4 \%) \text {, plantar } \\
\text { flexion }(52 \%) \text { and stepping } \\
\text { performance }(8.7 \%) \text { increased } \\
\text { significantly }\end{array}$ \\
\hline $\begin{array}{l}\text { Rampello et al. } \\
\text { Phys Ther [30] }\end{array}$ & $\begin{array}{c}\text { Nineteen subjects with mild to moderate disability secondary to MS } \\
\text { participated in a randomized crossover controlled study. Comparison } \\
\text { between the effects of aerobic training and the effects of a neurological } \\
\text { rehabilitation protocol }\end{array}$ & $\begin{array}{c}\text { After the AT, significant increase in } 3 \text { MSQOL-54 scale } \\
\text { scores After the NR program, significant improvements } \\
\text { in } 2 \text { MSQoL54 and a significant reduction in emotional } \\
\text { well-being scores. }\end{array}$ \\
\hline $\begin{array}{l}\text { Khan et al. } \\
\text { Cochrane Database Syst Rev [9] }\end{array}$ & $\begin{array}{c}49 \text { in and out - patients were treated with an individualised rehabilitation } \\
\text { programme for a mean duration of } 34 \text { days. They were compared with } 52 \\
\text { patients allocated in a control waitlist group }\end{array}$ & $\begin{array}{l}\text { Treated group improved in the } \\
\text { FIM motor scores }\end{array}$ \\
\hline $\begin{array}{l}\text { Pappalardo et al. } \\
\text { Mult Scler and Demyelinating Dis } \\
\text { [38] }\end{array}$ & $\begin{array}{c}\text { Two treated group compared with control waiting list. Treated patients were } \\
\text { divided into two groups: Group A outpatient, Group B inpatient }\end{array}$ & $\begin{array}{l}\text { Both outpatient and inpatient groups showed } \\
\text { significant improvement in FIM; only outpatient group } \\
\text { improved in SF-36- No changes in control group. }\end{array}$ \\
\hline $\begin{array}{l}\text { Broekmans et al. } \\
\text { Mult Scler [31] }\end{array}$ & $\begin{array}{l}11 \text { patients were treated only with standardized light to moderately intense } \\
\text { unilateral leg resistance training ; } 11 \text { patients with resistance training and } \\
\text { simultaneous electro-stimulation.; } 14 \text { were allocated in control group }\end{array}$ & $\begin{array}{c}\text { Maximal isometric knee extensor and knee flexor } \\
\text { strength increased; } \\
\text { dynamic muscle strength and } \\
\text { functional mobility did not } \\
\text { change; simultaneous electrostimulation does not } \\
\text { further improve training outcome }\end{array}$ \\
\hline $\begin{array}{l}\text { Collett et al. } \\
\text { Mult Scler [32] }\end{array}$ & $\begin{array}{l}\text { Sixty-one persons with MS were randomised and treated with different } \\
\text { exercise intensities. }\end{array}$ & $\begin{array}{l}\text { Fifty-five patients were included in the analysis. } \\
\text { Considering all participant, } 6 \text { weeks of cycling exercise } \\
\text { produces benefits in mobility }(2 \text { min. walk) that were } \\
\text { maintained with further sessions }\end{array}$ \\
\hline $\begin{array}{l}\text { Lozano-Quillis et al. } \\
\text { JMIR Serious Games [33] }\end{array}$ & $\begin{array}{l}\text { Randomized and controlled single blinded study carried out by the use of } \\
\text { RemoviEM, a system based on Kinect that uses virtual reality and natural } \\
\text { user interfaces. }\end{array}$ & $\begin{array}{l}\text { Significant group-by-time interaction was detected in } \\
\text { the scores of the Berg Balance Scale and the Anterior } \\
\text { Reach test in stnadingposition. Post-hocanalysis } \\
\text { showed greater improvement in the experimental } \\
\text { group for these variables than in control group }\end{array}$ \\
\hline
\end{tabular}




\begin{tabular}{|c|c|c|}
\hline $\begin{array}{c}\text { Plow et al. } \\
\text { Clin Rehabil [34] }\end{array}$ & $\begin{array}{l}\text { Participants were randomized to receive the intervention immediately } \\
(n=14) \text { or receive it at week } 12(n=16) \text {. Treatment consisted of home- } \\
\text { exercise program and following up with customized pamphlets, which were } \\
\text { matched to participants' stage of readiness to change physical activity } \\
\text { behaviour and physical activity barriers }\end{array}$ & $\begin{array}{l}\text { There were significant improvements in the immediate } \\
\text { group compared with the delayed group in physical } \\
\text { activity levels and health and function outcomes } \\
\text { (Godin Leisure-Time Exercise Questionnaire, SF-12, } \\
\text { Symptoms of Multiple Sclerosis Scale, and 6-minute } \\
\text { walk test) }\end{array}$ \\
\hline $\begin{array}{l}\text { Rietberg et al } \\
\text { Plos One [35] }\end{array}$ & $\begin{array}{l}\text { Forty-eight ambulatory MS patients with chronic fatigue were randomized } \\
\text { to individually tailored, multidisciplinary outpatient rehabilitation or to MS- } \\
\text { nurse consultation. }\end{array}$ & $\begin{array}{l}\text { Primary outcome measure was the Checklist Individual } \\
\text { Strength (CIS-20R), which showed no significant } \\
\text { differences between groups at } 12 \text { weeks and } 24 \\
\text { weeks. }\end{array}$ \\
\hline $\begin{array}{c}\text { Sangelaij et al } \\
\text { Iran Red Crescent Med [36] }\end{array}$ & $\begin{array}{l}\text { RCT on } 59 \text { patients divided into the intervention }(n=39) \text { and control groups } \\
(n=20) \text {. The intervention group received } 10 \text { weeks of combination therapy } \\
\text { including aerobic, strengthening, balancing and stretching exercises }\end{array}$ & $\begin{array}{l}\text { Significant changes in the intervention group in } \\
\text { comparison to the control group in the second phase } \\
\text { of the study comparing to the first one for Berg } \\
\text { Balance Test, Six-minute walking test and Fatigue } \\
\text { Severity Scale }\end{array}$ \\
\hline $\begin{array}{c}\text { Straudi et al } \\
\text { BMC Neurology [37] }\end{array}$ & $\begin{array}{c}24 \text { subjects randomly assigned to high-intensity rehabilitative task-oriented } \\
\text { circuit training (TOCT) over } 2 \text { weeks followed by a } 3 \text { months home exercise } \\
\text { program, whereas control group did not receive any specific rehabilitation } \\
\text { intervention }\end{array}$ & $\begin{array}{c}\text { After TOCT walking ability and health-related quality of } \\
\text { life were improved with minor retention after } 3 \text { months. } \\
\text { The control group showed no significant changes in } \\
\text { any variables. }\end{array}$ \\
\hline $\begin{array}{l}\text { Pappalardo et al. } \\
\text { Mult Scler and Demyelinating Dis } \\
\text { [38] }\end{array}$ & $\begin{array}{c}\text { Forty-nine PwMS were allocated in the outpatient treatment group (Group } \\
\text { A), } 49 \text { in the inpatients group (Group B) and } 48 \text { in the control waiting list } \\
\text { (Group C). PwMS were treated according to a protocol based on voluntary } \\
\text { exercises for neuromuscular control, aimed to improve muscle strength } \\
\text { of both upper and lower limbs, propiocetive sensibility, stability and } \\
\text { coordination for balance. These exercises were mainly task-oriented and } \\
\text { aimed to ameliorate the activities of daily living }\end{array}$ & $\begin{array}{l}\text { Both Group A and Group B showed significant } \\
\text { imrpovement in total FIM scores. No difference was } \\
\text { found between Group A and B with regard to the FIM } \\
\text { scores in the intergroups analysis. Group A showed } \\
\text { significant in all sub-items of SF-36, contrary to Group } \\
\text { B. A significant difference in total FIM score between } \\
\text { the three groups was found. }\end{array}$ \\
\hline
\end{tabular}

Table 1: Randomised controlled trials (RCT) in MS rehabilitation.

[22]. Freeman et al. found a positive effect on disability as assessed by the Functional Independence Measure (FIM) and a negligible effect on impairment. The benefits gained from rehabilitation were partly maintained after discharge, despite worsening of neurologic status [23]. With a chronic and progressive disease as MS, carry-over of benefits assumes a fundamental role. Patti et al. observed carry-over of benefits on disability for a further six weeks after a short outpatient treatment, without changing on impairment [27]. In Solari et al. study, physical rehabilitation determined improvement in disability detected by FIM motor domains and had a positive impact on mental components of HRQoL perception [25]. Kraft et al. performed a stratified, randomised, waitlist controlled study over 12 months, in which an individualised rehabilitation programme reduced disability as measured by FIM motor domains, while there were no differences between control and treatment group as regard to participation and QoL [12].

A randomised controlled trial involving 36 patients highlighted that long-term intense resistance training improved muscle strength (maximal isometric strength of both knee extensor and flexor muscles), but did not change dynamic muscle strength and functional mobility [31].

There is strong evidence in favour of exercise therapy compared to lack of exercise therapy in terms of muscle power function, exercise tolerance functions and mobility-related activities. These findings were highlighted in the Cochrane Review, which selected nine highmethodological-quality Randomized Controlled Trials (RCT) including 260 participants. No evidence was observed for exercise therapy on fatigue and perception of handicap [39]. Theoretically, persons with MS trend to reduce their physical activity, and this in turn could result in deconditioning across multiple domains of physiological functioning. The resulting deconditioning feeds back and further drives physical inactivity until a threshold is reached that likely begins the progression of walking impairment. Therefore, there is a conceptual rationale for exercise training, which must be included in a rehabilitative project [40].

IN regard to the occupational therapy, no conclusions can be stated whether it can improve outcome in PwMS [41]. This is partly due to the small number of included patients in the available studies, which evaluated an energy-conservation course for groups of patients and a counselling intervention. The results of the energy conservation studies were considered as biased because of the design used, whereas the studies on counselling did not report significant results. A more recent retrospective study concluded that inpatient occupational therapy improved FIM scores, exerting positive effect on functional performance in all categories except feeding, with significant correlation in upper extremity dressing and memory [42].

\section{Neuroscientific foundations of neurorehabilitation in MS}

Cortical reorganization: Brain plasticity is the capacity of central nervous system to adapt to new environmental challenges or anatomical damage [43]. Brain changes after cognitive rehabilitation were evaluated by using structural and functional magnetic resonance imaging techniques(fMRI).

This plastic changes, such as axonal sprouting, collateral pathways circumnavigating lesions in descending motor tracts and cortical adaptation may underlie the functional compensation in MS [44-45]. Lee et al. demonstrated that cortical recruitment for simple movements can change both quantitatively and qualitatively in sensorimotor cortex of MS patients. They hypothesized that cortical reorganization or "unmasking" of latent pathways could contribute to functional recovery [46]. The recruitment of additional cortical of the sensorimotor network was found to be confined to contralateral hemisphere in patients with scattered white matter lesions and no previous symptom of motor deficit [47]. Besides, this further recruitment involved also the ipsilateral sensorimotor network in patients with a previous hemiparesis and a larger number of lesions specifically located along the corticospinal tract [47].

This cortical reorganization was also demonstrated in patients with PPMS, who showed greater activation bilaterally in the superior temporal gyrus, ipsilaterally in the middle frontal gyrus, and, contralaterally in the insula/claustrum than health controls in fMRI during the execution of specific movement [48].

There are some other pieces of evidence in support of the 
adaptive changes involving reorganization of cortical representation in MS patients [49-54]. How this cortical reorganization responds to rehabilitative training has not been completely clarified. More specifically, neural substrates underlying new skills acquisition and relearning of lost functions in patients with MS are poorly understood. In Morgen's study, patients with MS and health volunteers underwent a motor training. Before training, motor tasks determined more prominent activation of contralateral dorsal premotor cortex in patients than in controls. After training, unlike the control group, patients with MS did not exhibit task-specific reductions in activation in contralateral primary somatosensory, motor and adjacent parietal association cortices. The main findings of this study were that motor training resulted in task-specific decreases in activation of controlateral cortical areas in controls but not in treated patients [54].

Motor learning and rehabilitation: Several studies highlighted improvements in upper limb function, gait or head control during variable lengths of training [55-58]. Some of these studies indicated that early in disease, MS subjects have intact adaptive capabilities, while the ability to learn motor skills may be progressively impaired with higher levels of disability [55,56], especially for tasks requiring a complex integration of sensory information [56].

Tomassini et al. pointed out different results, showing that the potential to learn a new motor skill is preserved in MS patients across a wide range of disability, as even most severely damaged patients were capable of performance improvements of similar magnitude to those seen in controls [59].

Cortical plasticity enhanced by motor and cognitive rehabilitation: Ibraham et al. studied the impact of rehabilitation (operator-assisted facilitation physiotherapy) on Fractional anisotropy (FA), mean diffusivity (MD), axial diffusivity $\lambda(\mathrm{ax})$, radial diffusivity $\lambda$ (rad) of the whole corpus callosum at baseline, patients with MS showed significantly lower values in FA and significantly higher values in $\mathrm{MD}, \lambda(\mathrm{ax})$ and $\lambda$ (rad) compared to control subjects. Differences 2 months after initiating facilitation physiotherapy were in FA, MD and in $\lambda$ (rad) significantly higher than differences in healthy controls. In MS patients, FA in the corpus callosum significantly increased while $\mathrm{MD}$ and $\lambda$ (rad) significantly decreased [60].

Very recently, Rasova et al. evaluated the effects of new kind of neurofacilitation approach, motor programme activating therapy (MPAT) with a set of clinical functions and with MRI. Eighteen patients underwent a $1 \mathrm{~h}$ session of MPAT, twice a week for 2 months. A significant improvement in clinical functions, significant increment of fractional anisotropy and significant decrement of mean diffusivity associated with a decrement of effective connectivity at supplementary motor areas was found immediately after the therapy. The modifications in clinical functions and diffusion tensor images were also observed one month after the end of rehabilitation [61].

Tomassini et al. stated that adaptive plasticity of MS patients is modulated by brain systems different than in health subjects. In this study, 23 patients with MS and 13 healthy individuals underwent shortterm and long-term training of a visuomotor task. Long term clinical improvement after intervention based on visuomotor task were related to changes in task-related activation in the left superior lobule and right lateral occipital cortex, while health subjects showed changes only in occipital cortex. Therefore, rehabilitation treatment based on voluntary movements may contribute to enhance functional and structural brain plasticity [62].

In agreement with this assertion, Bonzano et al. pointed out that rehabilitation based on active and voluntary exercises task-oriented, may induce microstructural modifications of white matter bundles involved in voluntary motor control. The effects of a training based on task-oriented motor rehabilitation (active group) were compared with those of a training based on passive motor exercises (passive group). In active group the bimanual coordination task remained stable, while worsened in passive group. Accordingly in fMRI, passive group, but not active one, showed reduced fractional anisotropy and increased radial diffusivity of corticospinal tracts and corpus callosum [63].

The hypothesis that structural plasticity may be stimulated in brain areas specifically involved in the function with task-oriented rehabilitation is supported by Prosperini et colleagues. A total of 36 patients affected by MS were subdivided in two counterbalanced groups: Group A underwent 30 min sessions, 5 days per week for 12 consecutive weeks of home-based video game training (intervention period), followed by a 12 week period without any specific intervention (observation period); Group B was treated in reverse order. Patients showed improvement of diffusion tensor imaging measures of superior cerebellar peduncles. Accordingly, there was also a clinical improvement of static balance [64].

Cognitive rehabilitation: Cognitive impairment is rather frequent in persons with MS: it has been reported that almost $40-65 \%$ of MS patients could suffer of decreased cognitive abilities. This may determine a profound impact on the patients social sphere and employability [65].

The cognitive areas involved in MS are quite variegated; patients mainly show a decreased speed in information processing and deficits of executive functions, attention and memory [66] .

The term cognitive rehabilitation was perhaps always too narrow, and focused too heavily on remediating or compensating for cognitive impairment. Although some of the fundamental goals of improving and compensating for cognitive abilities continue to be mainstays of rehabilitation efforts, the last 20 years have allowed richer appreciation for the influence of contextual variables such as personal, emotional and social impacts of the illness and their interaction with cognitive function. All these factors have been incorporated to an even greater degree into treatment plans and goals.

There are few randomised controlled trials focusing on the effectiveness of neuropsychological intervention in people with MS. In Thomas 's Cochrane, 16 studies were indentified and included, but no definite conclusions could be made from the review. Two small studies of cognitive behavioural therapy showed significant improvements in depression. To regard the cognitive impairment, three trials highlighted some evidence of effectiveness of cognitive rehabilitation, although this was difficult to interpret because of the large number of outcome measures used [67].

Jonsson et al. led a study on 40 patients with mild to moderate cognitive and behavioural impairment. After short-term treatment, effects on cognitive measures were rather mild, but on the Beck Depression Inventory (BDI) the specific cognitive treatment group reported significantly less depression. After 6 months, only this group showed an improvement on the visuo-spatial memory; the depression rating on BDI were almost maintained [68].

Plohmann et al. evaluated the effects of a specific computer based retraining of four attentional functions on cognitive measures in patients with mild to moderate cognitive dysfunction. Significant improvements of performance for the domains alertness and divided attention as well as increased performance in an aspect of selective attention were achieved by the respective training programmes. The increase of performance remained stable for at least nine weeks [69]. 
Benedict et al. carried out a study on 15 patients with marked cognitive impairment and behaviour disorder. Patients who underwent neuropsychological counselling showed significant positive response on measures of social behaviour (e.g. excessive ego-centric speech) [70].

Mattioli et al. conducted a study on a homogeneous group of Relapsing Remitting MS (RRMS) patients with low levels of disability and a stable clinical course in the previous year. Patients underwent an intensive ( $3 \mathrm{~h} /$ week for three consecutive months) cognitive rehabilitation procedure of information processing, attention and executive functions. After rehabilitation, only the treated group significantly improved in tests of attention and information processing, assessed by Paced Auditory Serial Addition Test and in executive functions, evaluated by the Winsconsin Card Sorting Test. The authors underlined the usefulness of intensive short duration specific therapy in persons with MS affected by cognitive deficits [71].

The intervention strategies consisted of training of attention determined an increased activation of the cerebral areas that are known to be involved in a network functionally related to attention processing. In a preliminary study, 11 patients with cognitive deterioration were treated with the AIXTENT software to train alertness, divided attention and selective attention. After the rehabilitative training, fMRI images showed an enhanced activation of regions in the cingulated gyrus, precuneus and frontal cortes [72].

Sastre-Garriga et al. observed an increased fMRI activation in right posterior lobe and posterior lobes of cerebellum in 15 patients after a mixed intervention, based on computer-aided training plus game-like group activities. Moreover, patients showed an improved performances in backward version of digit-span. Nevertheless, the authors did not find significant correlation between clinical and fMRI variations, likely because the small size of the sample [73].

More recently, Cerasa et al. carried out a double-blind, randomized, controlled trial, in which 13 patients, allocated in cognitive rehabilitation intervention group, underwent a computer-assisted training of several attention ability and information processing tasks, for twice a week, $1 \mathrm{~h}$ sessions for 6 consecutive weeks. After the training, the treated group showed a specific enhanced performances in attention abilities, as assessed by the Stroop task, coupled with enhanced activity in posterior cerebellar lobule and in superior parietal lobule [74].

To regard the rehabilitation strategies focused on memory deficits, Chiaravalloti and colleagues studied the effects of a rehabilitative approach called modified Story Memory Technique (mSMT). After intervention, greater activation was evident in treatment group during performance of a memory task within a widespread cortical network involving parietal, precuneus and paraippocampal areas, while control group showed no significant changes in cerebral activation. The authors also found a significant correlation between improved memory performances and enhanced activation of the right middle frontal gyrus, which is known to be associated with visual and context-dependent learning [75]. Afterwards, a subset of patients from this latter clinical trial underwent also Resting-State Functionally Connectivity-fMRI, in order to examine the connectivity within the neural networks associated with memory function. In conclusion, the authors hypothesized that cognitive rehabilitation would result in increased integrity of connections within two primary memory network, the hippocampal memory network and posterior cingulated cortex (default network) [76].

A French-study investigated the effects of cognitive rehabilitation on autobiographical memory. Four patients underwent a training based on the cueing role of mental visual imagery in autobiographical memory. After the rehabilitation, increased activation of posterior cerebral areas specifically involved in memory retrieval (right cuneus, left precuneus, left inferior and superior occipital gyri, left lateral temporal cortex) coupled with significant improvement of autobiographical memory performances were stated [77].

Finally, we report the issues of the studies focused on a wide range of cognitive domains, such as memory, executive functions, attentional processes and information processing speed.

Filippi et al. described the benefits of a 12 weeks training of cognitive rehabilitation in changing the recruitment of several brain areas that are mainly located in the frontal-parietal lobes. Patient underwent intensive computer-assisted cognitive rehabilitation of attention, information processing and executive functions for 12 weeks, performed by the use of a software included in the RehaCom Package with $1 \mathrm{~h}$ session for three-times per week. After training, fMRI demonstrated changes of the activity of posterior cingulated cortex, precuneus and dorsolateral prefrontal cortex during the execution of the Stroop Test, as well as changes of the activity of anterior cingulum, posterior cingulated cortex, precuneus left dorsolateral prefrontal cortex and right inferior parietal lobule at rest [78]. Clinically, patients showed an improvement in some tests of attention, information processing and executive functions. Subsequently, the same research group investigated how resting state functional connectivity (FC) of anterior cingulated cortex correlates with cognitive training. At follow-up, the anterior cingulum showed an increased FC with the right inferior parietal lobule and decreased FC with the right inferior temporal gyrus in the treated group only; some of these FC modifications significantly correlated to enhanced PASAT scores after the training [79].

Bonavita and colleagues studied the effects of short-term computer-based cognitive rehabilitation (cCR) on eighteen patients affetcted by RRMS, compared with a control group submitted to an aspecific cognitive training. After $\mathrm{CCR}$, patients showed a significant improvement of several cognitive tests exploring information processing speed and verbal and visual sustained memory, as well as a significant increase of the functional connectivity of the default mode network in the posterior cingulated cortex and bilateral inferior parietal cortex . Control group did not show and significant variations on either cognitive performances or functional connectivity [80].

Recently, De Giglio et al. investigated the effects of an 8 week homebased rehabilitation program by use of the Dr. Kawashima Nintendo Brain Training, an educational video game ended to train memory, attention, visuospatial processing and calculations. After this training, patients showed increased thalamic connectivity in cortical areas that partially overlapped the posterior component of default mode-network. The increased connectivity positively correlated with improvement of cognitive performances (i.e., sustained and divided attention and some aspects of executive functions), suggesting that changes in thalamic functional connectivity induced by cognitive rehabilitation may represent a functional substrate underlying clinical recovery [81].

Rehabilitation setting: It remains unsolved the question regarding the most suitable rehabilitative setting for PwMS. In this regard, it must be considered not only the efficacy of treatment but also the evidences encompassing the long-term cost-effectiveness.

There are four possible options for the rehabilitative treatment setting in which the patient could be allocated: i) home based therapy, ii) outpatient ambulatory therapy, iii) inpatient hospitalised therapy, iiii) outpatient hospitalised therapy. Specific guidelines, ended to a 
rational allocation of PwMS in rehabilitative setting are not available yet. Moreover, there are very few studies comparing the effects of different rehabilitative settings.

Waying back in 1988, a study was conducted to compare the effects of inpatient and outpatient rehabilitation upon functional status. Patients were evaluated using the Incapacity Status Scale and a structured interview. The conclusion of the study showed the effectiveness of inpatient rehabilitation in producing a significant reduction of disability, as compared to outpatient treatment [21].

Very recently, a RCT was performed to investigate the rehabilitation efficacy in terms of functional independence and HRQoL between two different settings. Both inpatient and outpatient settings showed significant improvement in functional independence but only outpatient setting was found to be effective in improving HRQoL [38].

Almost of all of the studies analyse the results of one rehabilitative setting, in comparison with no treated control group (Table 1). Inpatient setting was associated with a significant improvement in functional impairment [], disability [23], functional independence [25,38] and HRQoL $[25,26]$. Trials conducted in outpatient setting demonstrated effectiveness of rehabilitation in improvement of muscular strength [22], walking capacity [30], functional independence [27,38], HRQoL $[22,24,26]$. Home-based rehabilitation produced significant improvement in HRQoL $[34,82,83]$, balance $[36,64,84]$, leg estensor power [85], gait parameters [34], fatigue [36].

Below, we report the conclusions of several systematic reviews which searched to assess the effectiveness of multidisciplinary rehabilitation in PwMS to explore rehabilitation approaches in different settings.

Khan et al. reviewed the results of ten trials ( 9 randomized controlled trials and 1 controlled clinical trial) in 2011, asserting the strong evidence to support inpatient multidisciplinary rehabilitation in producing short-terms gains at the levels of activity (disability) and participation of PwMS. As regards outpatient and home-based rehabilitation programmes, they found a limited evidence for short term improvements in symptoms and disability with high intensity programmes, which translated into improvement in participation and quality of life. For low intensity programmes, there was strong evidence for longer-term gains in quality of life [9].

Haselkorn et al. reviewed 491 articles appeared from 1970 to 2013. They asserted that weekly home/outpatient physical therapy probably is effective for improving balance, disability and gait but probably is ineffective for improving upper extremity dexterity. Inpatient exercises followed by home exercises possibly are effective for improving disability and six weeks' worth of comprehensive multidisciplinary outpatient rehabilitation possibly is effective for improving disability/function. Motor and sensory balance training or motor balance training possibly is effective for improving static and dynamic balance, and motor balance training possibly is effective for improving static balance [86].

Outocome instruments: Appropriateness of outcome measure in rehabilitation is essential. Some results from rehabilitation in MS could be controversial because the use of unsuitable outcome measures. To bring an example, Romberg et al. found that a long term exercise program determined significant improvement in leg function and ambulation. These changes could be assessed with Multiple Sclerosis Functional Composite (MSFC), whereas no significant effects were seen with the Expanded Disability Status Scale [82]. In a recent metaanalysis for the period 1960-2006, Motl et al. observed a significant effect of aerobic exercise on improving the QoL. These effects were statistically significant when using an MS-specific QoL instrument, whereas there was no significant effect when generic QoL measures were used. The differences may be due to the fact that only MS-specific QoL instruments would be able to capture all peculiar aspects of QoL impacted by the rehabilitation, for a particular patient population such as with MS [40].

Therefore, it plays a crucial importance to set targets achievable with the rehabilitation and even more, to select the most sensitive assessment instruments.

\section{Conclusion}

MS is perhaps the most multifaceted disease among those that cause chronic health disorders. Living with the MS is a great challenge which changes the view of life, either for the patient or for his relatives, mainly because:

a) the disease affects young people over the more productive lifetime.

b) the life expectancy is not substantially shortened.

Rehabilitation management looks at the "person with MS" rather than just the disease. Rehabilitation aims to maximize the functional independence, through stabilization of functioning, reduction of disability and prevention of secondary complications. These objectives can be achieved through an educational process that encourages the functional independence of the individual. Rehabilitation is a process of active change by which a disabled person acquires new skills, needed to optimize his/her physical and psychological functions. In addition, a detailed assessment of cognitive domains is remarkably important in persons with MS, in order to identify specific deficits and enable a targeted neuropsychological intervention. In this context, the prospect of cognitive rehabilitation offers interesting possibilities, even if further larger randomised studies are needed. Lastly but not least, it must improve personal activities and ability to participate in social activities, thereby improving quality of life [87].

Rehabilitation in MS could offer the patients different options of treatment: inpatient, outpatient, home based, etc. on the basis of their desires and preferences, after evaluating family resource and life place. Treatment should be adapted depending on: the individual patient's needs, demands of their surrounding environment, type and degree of disability and treatment goals. Besides, we must take into account not only of medical problems but also social and familiar aspects. In other words, it is indispensable to take into account familiar resources, having or not having children, being or not being child of old and ill parents, have the capacity to produce an income, live or not live in rural or urban areas, have problems with travelling to the centre for rehabilitation, etc.

The best knowledge of more properly individual requirements can, without any doubt, contribute to promote perception and acceptance of rehabilitation as valuable treatment options in persons with MS.

\section{References}

1. World Health Organization (2004) Results of a collaborative study of World Health Organization and World federation of neurology. Programme for Neurological Diseases and Neurosciences Department of Mental Health and Substance Abuse. Geneva: World Health Organization.

2. Nortvedt MW, Riise T, Myhr KM, Nyland HI (1999) Quality of life in multiple sclerosis: measuring the disease effects more broadly. Neurology 53: 1098-1103.

3. (1998) Burden of illness of multiple sclerosis: Part II: Quality of life. The Canadian Burden of Illness Study Group. Can J Neurol Sci 25: 31-38.

4. Murphy N, Confavreux C, Haas J, Konig N, Roullet E, et al. (1998) Quality of life in multiple sclerosis in France, Germany, and the United Kingdom. Cost of Multiple Sclerosis Study Group. J Neurol Neurosurg Psychiatry 65: 460-466. 
Citation: Pappalardo A, D'Amico E, Chisari C, Patti F (2016) Neurorehabilitation in Persons with Multiple Sclerosis: Scientific Basis and Options of Treatment. J Mult Scler (Foster City) 3:186. doi:10.4172/2376-0389.1000186

Page 7 of 8

5. Solari A, Radice D (2001) Health status of people with multiple sclerosis: A community mail survey. Neurol Sci 22: 307-315.

6. Morales-Gonzales JM, Benito-Leon J, Rivera-Navarro J, Mitchell AJ (2004) A systematic approach to analyse health-related quality of life in multiple sclerosis: The GEDMA study. Mult Scler 10: 47-54.

7. Lublin FD, Reingold SC, Cohen JA, Cutter GR, Sørensen PS, et al. (2014) Defining the clinical course of multiple sclerosis: The 2013 revisions. Neurology 83: $278-286$

8. Frohman EM, Racke M, van Den Noort S (2000) To treat or not to treat: The therapeutic dilemma of idiopathic monosymptomatic demyelinating syndromes. Arch Neurol 57: 930-932.

9. Khan F, Turner Stokes L, Ng L, Kilpatrick T, Amatya B (2007) Multidisciplinary rehabilitation for adults with multiple sclerosis (Review). Cochrane Database Syst Rev 2: CD006036.

10. Putnam M, Tang $F(2008)$ Long-term care planning and preparation among persons with multiple sclerosis. Home Health Care Serv Q 27: 143-165.

11. Cohen BA (2008) Identification, causation, alleviation and prevention of complications (ICAP): An approach to symptom and disability management in multiple sclerosis. Neurology 71: S14-S20.

12. Kraft GH, Johnson KL, Yorkston K, Amtmann D, Bamer A, et al. (2008) Setting the agenda for multiple sclerosis rehabilitation research. Mult Scler 14: 12921297.

13. Patti F, Pappalardo A (2010) Quality of Life in Patients Affected by Multiple Sclerosis: A Systematic Review. In: Handbook of Disease Burdens and Quality of Life Measures. Springer.

14. Citrinovitz J (1957) Physical therapy and rehabilitation in multiple sclerosis. Dia Med 29: 1390

15. Hoeck E (1963) Physical therapy and acth treatment of multiple sclerosis. Munch Med Wochenschr 105: 1683-1688.

16. Young RF, Goodman SJ (1979) Dorsal spinal cord stimulation in the treatmen of multiple sclerosis. Neurosurgery 5: 225-230.

17. Gehlsen GM, Grigsby SA, Winant DM (1984) Effects of an aquatic fitness program on the muscular strength and endurance of patients with multiple sclerosis. Phys Ther 64: 653-657.

18. Gehlsen G, Beekman K, Assmann N, Winant D, Seidle M, et al. (1986) Gait characteristics in multiple sclerosis: Progressive changes and effects of exercise on parameters. Arch Phys Med Rehabil 67: 536-539.

19. Davis R, Emmonds SE (1992) Spinal cord stimulation for multiple sclerosis: Quantifiable benefits. Stereotact Funct Neurosurg 58: 52-58.

20. Svensson B, Gerdle B, Elert J (1994) Endurance training in patients with multiple sclerosis: Five case studies. Phys Ther 74: 1017-1026.

21. Fracabandera FL, Holland NJ, Wiesel-Levison P, Scheinberg LC (1988) Multiple sclerosis rehabilitation: Inpatient vs. Outpatient. Rehabilitation Nursing 13: 251-253

22. Petajan JH, Gappmaier E, White AT, Spencer MK, Mino L, et al. (1996) Impact of aerobic training on fitness and quality of life in multiple sclerosis. Ann Neurol 39: 432-441.

23. Freeman JA, Langdon DW, Hobart JC, Thompson AJ (1997) The impact of inpatient rehabilitation on progressive multiple sclerosis. Ann Neurol 42: 236-

24. Di Fabio RP, Choi T, Soderberg J, Hansen CR (1997) Health-related quality of life for patients with progressive multiple sclerosis: Influence of rehabilitation. Phys Ther 77: 1704-1716.

25. Solari A, Filippini G, Gasco P, Colla L, Salmaggi A, et al. (1999) Physical rehabilitation has a positive effect on disability in multiple sclerosis patients. Neurology 52: 57-62.

26. Patti F, Ciancio MR, Reggio E, Lopes R, Palermo F, et al. (2002) The impact of outpatient rehabilitation on quality of life in multiple sclerosis. J Neurol 249 1027-1033.

27. Patti F, Ciancio MR, Cacopardo M, Reggio E, Fiorilla T, et al. (2003) Effects of a short outpatient rehabilitation treatment on disability of multiple sclerosis patients-a randomised controlled trial. J Neurol 250: 861-866.

28. Craig J, Young CA, Ennis M, Baker G, Boggild M (2003) A randomised controlled trial comparing rehabilitation against standard therapy in multiple sclerosis patients receiving intravenous steroid treatment. J Neurol Neurosurg Psychiatry 74: 1225-1230.

29. White LJ, McCoy SC, Castellano V, Gutierrez G, Stevens JE, et al. (2004) Resistance training improves strength and functional capacity in persons with multiple sclerosis. Mult Scler 10: 668-674.

30. Rampello A, Franceschini M, Piepoli M, Antenucci R, Lenti G, et al. (2007) Effect of aerobic training on walking capacity and maximal exercise tolerance in patients with multiple sclerosis: A randomized crossover controlled study. Phys Ther 87: 545-855.

31. Broekmans T, Roelants M, Feys P, Alders G, Gijbels D, et al. (2010) Effects of long-term resistance training and simultaneous lector-stimulation on muscle strength and functional mobility in multiple sclerosis. Mult Scler 17: 468-477.

32. Collett J, Dawes H, Meaney A, Sackley C, Barker K, et al.(2011) Exercise for multiple sclerosis: A single-blind randomized trial comparing three exrcise intensities. Mult Scler 17: 594-603.

33. Lozano-Quilis JA, Gil-Gómez H, Gil-Gómez JA, Albiol-Pérez S, Palacios-Navarro $\mathrm{G}$, et al. (2014) Virtual rehabilitation for multiple sclerosis using a kinect-based system: Randomized controlled trial. JMIR Serious Games 12: e12.

34. Plow M, Bethoux F, McDaniel C, McGlynn M, Marcus B (2014) Randomized controlled pilot study of customized pamphlets to promote physical activity and symptom self-management in women with multiple sclerosis. Clin Rehabil 28 139-148.

35. Rietberg MB, van Wegen EEH, Eyssen ICJM, Kwakkel G (2014) Effects of multidisciplinary rehabilitation on chronic fatigue in multiple sclerosis. A randomized controlled trial. Plos One 9: e1077.

36. Sangelaji B, Nabawi SM, Estebsari F, Banshi MR, Rashidian H, et al. (2014) Effect of combination exercise therapy on walking distance, postural balance, fatigue and quality of life in multiple sclerosis patients: A clinical trial study. Crescent Med J 16: e17173.

37. Straudi S, Martinuzzi C, Pavarelli C, Sabbagh Charabati A, et al. (2014) A taskoriented circuit training in multiple sclerosis: A feasibility study. BMC Neurol 14: 124

38. Pappalardo A, D'Amico E, Leone C, Messina S, Chisari C, et al (2016) Inpatien versus outpatient rehabiitation for multiple sclerosis patients: Effects on disability and qualtiy of life. Multiple Sclerosis and Demylinating Disorders 1: 3

39. Rietberg MB, Brooks D, Uitdehaag BM, Kwakkel G (2005) Exercise therapy for multiple sclerosis. Cochrane Database Syst Rev CD003980.

40. Motl RW, Goldman MD, Benedict RH (2010) Walking impairment in patients with multiple sclerosis: Exercise training as a treatment option. Neuropsychiat Dis Treat 6: 767-774.

41. Steultjens EM, Dekker J, Bouter LM, Cardol M, Van de Nes JC, et al. (2003) Occupational therapy for multiple sclerosis. Cochrane Database Syst Rev CD003608.

2. Maitra K, Hall C, Kalish T, Anderson M, Dugan E, et al. (2010) Five years retrospective study of inpatient occupational therapy outcomes for patients with multiple sclerosis. Am J Occup Ther 64: 689-694.

43. Jacobs KM, Donoghue JP (1991) Reshaping the cortical motor map by unmasking latent intracortical connections. Science 251: 944-947.

44. Reddy $\mathrm{H}$, Narayanan S, Arnoutelis $\mathrm{R}$, Jenkinson M, Antel J, et al. (2000) Evidence for adaptive functional changes in the cerebral cortex with axonal injury from multiple sclerosis. Brain 123: 2314-2320.

45. Pantano P, lannetti GD, Caramia F, Mainero C, Di Legge S, et al.(2002) Cortical motor reorganization after a single attack of multiple sclerosis. Brain 125: 1607 1615.

46. Lee $M$, Reddy $H$, Johansen-Berg $H$, Pendlebury S, Jenkinson M, et al.(2000) Motor cortex shows adaptive functional changes to brain injury from multiple sclerosis. Ann Neurol 47: 606-613.

47. Pantano P, Mainero C, lannetti GD, Caramia F, Di Legge S, et al. (2002) Contribution of cortical tract damage to cortical motor reorganization after a single clinical attack of multiple sclerosis. Neuroimage 17: 1837-1843.

48. Filippi M, Rocca MA, Falini A, Caputo D, Ghezzi A, et al. (2002) Correlations between structural CNS damage and functional MRI changes in primary progressive MS. Neuroimage 15: 537-546.

49. Bruck W(2005) The pathology of multiple sclerosis is the result of focal inflammatory demyelination with axonal damage. J Neurol 252: v3-v9. 
Citation: Pappalardo A, D’Amico E, Chisari C, Patti F (2016) Neurorehabilitation in Persons with Multiple Sclerosis: Scientific Basis and Options of Treatment. J Mult Scler (Foster City) 3:186. doi:10.4172/2376-0389.1000186

Page 8 of 8

50. Mezzapesa DM, Rocca MA, Rodegher M, Comi G, Filippi M, et al.(2008) Functional cortical changes of the sensorimotor network are associated with clinical recovery in multiple sclerosis. Hum Brain Mapp 29: 562-573.

51. Stefan K, Kunesch E, Cohen LG, Cohen LG, Classen J, et al.(2000) Induction of plasticity in the human motor cortex by paired associative stimulation. Brain 123: $572-584$.

52. Reddy H, Narayanan S, Woolrich M, Mitsumori T, Lapierre Y, et al. (2002) Functional brain reorganization for hand movement in patients with multiple sclerosis: Defining distinct effects of injury and disability. Brain 125: 2646-2657.

53. Rocca MA, Falini A, Colombo B, Scotti G, Comi G, et al. (2002) Adaptive functional changes in the cerebral cortex of patients with non disabling multiple sclerosis correlate with the extent of brain structural damage. Ann Neurol 51: 330-339.

54. Morgen K, Kadom N, Sawaki L, Tessitore A, Ohayon J, et al. (2004) Trainingdependent plasticity in patients with multiple sclerosis. Brain 127: 2506-2517.

55. Casadio M, Sanguineti V, Morasso P, Solaro C (2008) Abnormal sensori motor control, but intact force field adaptation in multiple sclerosis subjects with no clinical disability. Mult Scler 14: 330-342.

56. Leocani L, Comi E, Annovazzi P, Rovaris M, Rossi P, et al.(2007) Impaired short-term motor learning in multiple sclerosis: Evidence from virtual reality. Neurorehabil Neural Repair 21: 273-278.

57. Hatzitaki V, Koudouni A, Orologas A (2006) Learning of a novel visuo-postura co-ordination task in adults with multiple sclerosis. J Rehabil Med 38: 295-301.

58. CattaneoD, Ferrarin M, Frasson W, Casiraghi A (2005) Head control: Volitional aspects of rehabilitation training in patients with multiple sclerosis compared with healthy subjects. Arch Phys Med Rehabil 86: 1381-1388.

59. Tomassini V, Johansen-Berg H, Leonardi L, Paixão L, Jbabdi S, et al. (2011) Preservation of motor skill learning in patients with multiple sclerosis. Mult Scler 17: 103-115

60. Ibrahim I, Tintera J, Skoch A (2011) Fractional anisotropy and mean diffusivity in the corpus callosum of patients with multiple sclerosis: the effect of physiotherapy. Neuroradiology 53: 917-926.

61. Rasova K, Prochazkova M, Tintera J, Ibrahim I, Zimova D, et al. (2015) Motor programme activating therapy influences adaptive brain functions in multiple sclerosis: clinical and MRI study. International Journal of Rehabilitation Research 38: 49-54.

62. Tomassini V, Johansen-Berg H, Jbabdi S, Wise RG, Pozzilli C, et al. (2012) Relating brain damage to brain plasticity in patients with multiple sclerosis. Neurorehabilitation \& Neural Repair 26: 581-593.

63. Bonzano L, Tacchino A, Brichetto G, Roccatagliata L, Dessypris A, et al. (2014) Upper limb motor rehabilitation impacts white matter microstructure in multiple sclerosis. Neurolmage 90: 107-116.

64. Prosperini L, Fanelli F, Petsas N, Sbardella E, Tona F (2014) Multiple sclerosis: Changes in microarchitecture of white matter tracts after training with a video game balance board. Radiology 273: 529-538.

65. Rao SM, Leo GJ, Ellington L, Nauertz T, Bernardin L, et al. (1991) Cognitive dysfunction in multiple sclerosis. II. Impact on employment and social functioning. Neurology 41: 692-696.

66. Rao SM, Leo GJ, Bernardin L, Unverzagt F (1991) Cognitive dysfunction in multiple sclerosis. I. Frequency, patterns and prediction. Neurology 41: 685691.

67. Thomas PW, Thomas S, Hillier C, Galvin K, Baker R (2006) Psychological interventions for multiple sclerosis. Cochrane Database Syst Rev CD004431.

68. Jonsson A, Korfitzen EM, Heltberg A, Ravnborg MH, Byskov-Ottosen E (1993) Effects of neuropsychological treatment in patients with multiple sclerosis. Acta Neurol Scand 88: 394-400.

69. Plohmann AM, Kappos L, Ammann W, Thordai A, Wittwer A, et al. (1998)
Computer assisted retraining of attentional impairments in patients with multiple sclerosis. J Neurol Neurosurg Psych 64: 455-462.

70. Benedict RH, Shapiro A, Priore R, Miller C, Munschauer F, et al. (2000) Neuropsychological counselling improves social behaviour in cognitivelyimpaired multiple sclerosis patients. Mult Scler 6: 391-396.

71. Mattioli F, Stampatori C, Bellomi F, Capra R, Rocca M, et al. (2010) Neuropsychological rehabilitation in adult multiple sclerosis. Neurol Sci 31: S271-274.

72. Penner IK, Kappos L (2006) Retraining attention in MS. J Neurol Sci 245: 147151.

73. Sastre-Garriga J, Alonso J, Renom M, Arevalo MJ, Gonzales I, et al. (2011) A functional magnetic resonance proof of concept pilot trial of cognitive rehabilitation in multiple sclerosis. Multiple Sclerosis 17: 457-467.

74. Cerasa A, Gioia MC, Valentino P, Nisticò R, Chiriaco C, et al.(2013) Computerassisted cognitive rehabilitation of attention deficits for multiple sclerosis: A randomized trial with fMRI correlates. Neurorehabilitation and Neural Repair 27: 284-295.

75. Chiaravalloti ND, Wylie G, Leavitt V, DeLuca J (2012) Increased cerebra activation after behavioral treatment for memory deficits in MS. Journal of Neurology 259: 1337-1346.

76. Leavitt VM, Wylie GR, Girgis PA, Deluca J, Chiaravalloti ND (2012) Increased functional connectivity within memory networks following memory rehabilitation in multiple sclerosis. Brain Imaging and Behavior 8: 394-402.

77. Ernst A, Botzung A, Gounot D, Sella F, Blanc F, et al (2012) Induced brain plasticity after a facilitation programme for autobiographical memory in multiple sclerosis: a preliminary study. Multiple Sclerosis International 820240.

78. Filippi M, Riccitelli G, Mattioli F, Capra R, Stampatori C, et al. (2012) Multiple sclerosis: Effects of cognitive rehabilitation on structural and functional MR imaging measures-an explorative study. Radiology 262: 932-940.

79. Parisi L, Rocca MA, Valsasina P, Panicari L, Mattioli F (2014) Cognitive rehabilitation correlates with the functional connectivity of the anterior cingulate cortex in patients with multiple sclerosis. Brain Imaging Behav 8: 387-393.

80. Bonavita S, Sacco R, Della Corte M, Esposito S, Sparaco M, et al. (2015) Computer-aided cognitive rehabilitation improbe cognitive performances and induces brain functional connectivity changes in relapsing remitting multiple sclerosis patients: An exploratorfy study. J Neurol 262: 91-100.

81. De Giglio L, Tona F, Petsas N, De Luca F, Prosperini L, et al. (2015) Changing in talami resting-state functional connectivity induced by a home-based cognitive. Proceedings of the 20th Annual RIMS conference Milan.

82. Romberg A, Virtanen A, Ruutiainen J (2005) Long-term exercise improves functional impairment but not quality of life in multiple sclerosis. J Neurol 252 839-845.

83. Pozzilli C, Brunetti M, Amicosante AM, Gasperini C, Ristori G, et al (2002) Home based management in multiple sclerosis, results of a randomised controller trial. J Neurol Neurosurg Psychiatry 73: 250-255.

84. Finkelstein J, Lapshin O, Castro H, Cha E, Provance PG (2008) Home-based physical telerehabilitation in patients with multiple sclerosis: A pilot study. J Rehabil Res Dev 45: 1361-1373.

85. DeBolt LS, McCubbin JA (2004) The effects of home-based resistance exercise on balance, power and mobility in adults with multiple sclerosis. Arch Phys Med Rehabil 85: 290-297.

86. Haselkorn JK, Hughes C, Rae-Grant A, Henson LJ, Bever CT, et al. (2015) Summary of comprehensive systematic review: Rehabilitation in multiple sclerosis: Report of the guideline development, dissemination and implemantation subcommittee of the American Academy of Neurology. Neurology 85: 1896-1903.

87. Kesselring J, Beer S (2005) Symptomatic therapy and neurorehabilitation in multiple sclerosis. Lancet Neurol 4: 643-652. 